\title{
Cholesterol and polyenoic fatty acids in liver, serum and aorta of rabbits given purified diets with butter, some margarines and arachis oil
}

\author{
By B. KROGH, J. P. FUNCH AND H. DAM \\ Department of Biochemistry and Nutrition, Polytechnic Institute, Copenhagen
}

(Received 7 December 1960-Revised 21 fune 1961)

The object of the experiment reported here was the study of the influence of butter, arachis oil or three mixtures of fats made into margarines on the cholesterol levels and fatty-acid compositions of liver, serum and aorta in rabbits fed on purified diets without added cholesterol. It was further intended to study whether high values for serum cholesterol were associated with marked atheromatous lesions in the aortas, and whether the severity of atherosclerosis was correlated with the amount of cholesterol in the aorta.

\section{EXPERIMENTAL}

The analyses reported here were made on serum and tissues from the rabbits used in the experiment of Funch, Krogh \& Dam (1960) which dealt with serum lipids and atherosclerosis in rabbits.

Male rabbits, 6 months old, were distributed over five groups of nine animals each. The rabbits were fed ad lib. for 42 weeks on purified diets containing $20 \%$ fat. The composition and constitution of the dietary fats are shown in Table I. For compositions of the diets and further experimental conditions, see Funch et al. (I960).

At the end of 42 weeks' feeding the rabbits were anaesthetized with ether, and blood was withdrawn from the heart until death ensued. The aorta was cleaned of fat on the adventitial surface, and the severity of atherosclerosis was graded on a scale of o to 4 (Funch et al. 1960). Liver, serum and aorta were frozen and stored at $-20^{\circ}$ until analysed. Since the atheromatous lesions occurred primarily in the thoracic region of the aorta, only this region was used for the analyses.

The liver was saponified with $30 \%(\mathrm{w} / \mathrm{v})$ aqueous $\mathrm{KOH}$ on a steam-bath for $2 \frac{1}{2} \mathrm{~h}$, and a measured quantity of the saponified mixture was extracted three times with light petroleum (b.p. $<50^{\circ}$ ). The combined petroleum extracts were washed, dried with anhydrous $\mathrm{Na}_{2} \mathrm{SO}_{4}$, filtered and evaporated. The residue was dissolved in chloroform and the cholesterol content was determined by the Liebermann-Burchard colour reaction. The aqueous phase from the petroleum extraction was acidified with conc. $\mathrm{HCl}$, extracted with light petroleum (b.p. $<50^{\circ}$ ), washed, dried with anhydrous $\mathrm{Na}_{2} \mathrm{SO}_{4}$, filtered and evaporated under reduced pressure, and the total fatty acids were then weighed. The polyenoic fatty acids in the liver fatty acids were estimated by the alkali-isomerization procedure described by Hammond \& Lundberg (r953). The iodine value of the liver fatty acids was determined by the method of Wijs. 
Serum was saponified with a mixture of $30 \%(\mathrm{w} / \mathrm{v})$ aqueous $\mathrm{KOH}$ and $96 \%$ ethanol $(\mathrm{I}: 2)$ on a steam-bath for $2 \frac{1}{2} \mathrm{~h}$. The unsaponifiable matter was extracted with diethyl ether. The ether extract was washed, and the aqueous phase from the washings was added to the main portion of the aqueous solution of the soaps, and the whole acidified with conc. $\mathrm{HCl}$ and extracted three times with light petroleum (b.p. $<50^{\circ}$ ). The combined petroleum extract was washed, dried with anhydrous $\mathrm{Na}_{2} \mathrm{SO}_{4}$, filtered and evaporated under reduced pressure at room temperature. The serum total fatty acids were weighed, and polyenoic fatty acids were determined by the method used for the liver fatty acids.

\section{Table I. Percentage composition and constitution of the dietary fats}

\begin{tabular}{|c|c|c|c|c|c|}
\hline & & Margari & & & \\
\hline Dietary fat & $\mathbf{M}_{1}$ & $\mathrm{M}_{2}$ & $\mathbf{M}_{3}$ & Butter & Arachis oil \\
\hline Hydrogenated whale oil (m.p. $40-42^{\circ}$ ) & 30 & - & 30 & - & - \\
\hline Hydrogenated whale oil (m.p. $30-32^{\circ}$ ) & - & 75 & - & - & - \\
\hline Coconut oil & 45 & - & - & - & - \\
\hline Rapeseed oil & 25 & 25 & 25 & - & - \\
\hline Cottonseed oil & - & - & 45 & - & - \\
\hline Vitamin A (i.u./g dietary fat) & $36 \cdot 6$ & $36 \cdot 8$ & $36 \cdot 6$ & * & $36 \cdot 0$ \\
\hline Carotene (i.u./g dietary fat) & $4 \cdot 2$ & 4.2 & $4 \cdot 2$ & * & $4 \cdot 0$ \\
\hline Vitamin $\mathrm{D}$ (i.u./g dietary fat) & $\mathrm{I} \cdot 8$ & $x \cdot 8$ & $\mathrm{r} \cdot 8$ & * & $i \cdot 8$ \\
\hline Polyenoic fatty acids ( $g / 100 \mathrm{~g}$ fat) $\dagger$ & & & & & \\
\hline Dienoic $\quad(a)$ & $7 \cdot 5$ & 4.9 & $19 \cdot 0$ & $\mathbf{2} \cdot \mathbf{3}$ & $24 \cdot 5$ \\
\hline (b) & $4 \cdot 6$ & $2 \cdot 8$ & $23 \cdot 2$ & $\mathbf{2} \cdot \mathbf{2}$ & $20 \cdot 6$ \\
\hline Trienoic $(a)$ & $3 \cdot 2$ & $2 \cdot 0$ & $2 \cdot 9$ & 0.7 & I.I \\
\hline (b) & $2 \cdot 6$ & $2 \cdot I$ & $2 \cdot 7$ & 0.6 & 0.5 \\
\hline Tetraenoic $(a)$ & $0 \cdot 0$ & $0 \cdot 0$ & 0.0 & 0.3 & 0.1 \\
\hline$(b)$ & 0.0 & 0.0 & 0.0 & 0.3 & 0.1 \\
\hline Pentaenoic $(a)$ & 0.0 & 0.0 & 0.0 & $0 \cdot z$ & 0.0 \\
\hline$(b)$ & 0.0 & 0.0 & $0 \cdot 0$ & 0.2 & 0.0 \\
\hline Hexaenoic $(a)$ & 0.2 & 0.0 & $0 \cdot \mathbf{I}$ & 0.2 & 0.0 \\
\hline$(b)$ & 0.1 & 0.2 & 0.0 & 0.0 & $0 \cdot 0$ \\
\hline Iodine value $(\mathrm{Wijs})(a)$ & 52 & 75 & 76 & $3 I$ & 94 \\
\hline (b) & 49 & 69 & 90 & $3 \mathrm{I}$ & 89 \\
\hline
\end{tabular}

(a) Values in samples used during the first 26 weeks of experiment; $(b)$ values in samples used during the last 16 weeks of experiment.

* Not determined in the samples used in this experiment, in which summer butter was used during the first 26 weeks and winter butter during the last 16 weeks. The vitamin $A$ and carotene content has previously been found to be: in summer butterfat, vitamin A 33.3 i.u./g and carotene 8.4 i.u./g; in winter butterfat, vitamin A I $5 \cdot 1$ i.u./g and carotene $\mathrm{r} \cdot 6 \mathrm{i} . \mathrm{u} . / \mathrm{g}$.

$\uparrow$ Estimated by the alkali-isomerization procedure described by Hammond \& Lundberg (r953). Figures obtained by this method on hydrogenated fat may be used for guidance and comparison, but the validity of the absolute values remains to be established.

The thoracic aorta was extracted three successive times at room temperature for 4,20 and $20 \mathrm{~h}$ with chloroform-methanol (2:I) in a glass-stoppered bottle in a shaker. The extract was filtered. Measured portions were evaporated for determination of cholesterol by the method of Herrmann (1957). Total lipid was determined by evaporation of measured portions to constant weight. The lipids extracted from the thoracic aortas of the rabbits from any one group were pooled, and polyenoic fatty acids and iodine values were determined by the methods used for liver fatty acids.

Because the values had a tendency to a skew distribution it was considered necessary 
for the statistical evaluation to carry out a logarithmic transformation to obtain an approximately normal distribution. By this procedure the variances of the distributions became independent of the new values and with one exception (aortic cholesterol content, cf. Table 4 ) became similar for all groups (Hald, I952a,b). Consequently, it

Table 2. Mean values for liver cholesterol, liver total fatty acids, iodine value and polyenoic fatty acids in the liver fatty acids of rabbits after 42 weeks

\begin{tabular}{|c|c|c|c|c|c|c|c|}
\hline \multirow[b]{2}{*}{$\begin{array}{c}\text { Group } \\
\text { no. }\end{array}$} & \multirow[b]{2}{*}{ Dietary fat } & \multicolumn{3}{|c|}{ Total fatty } & \multicolumn{3}{|c|}{$\begin{array}{l}\text { Polyenoic fatty acids } \\
\text { (g/roo g fatty acids) }\end{array}$} \\
\hline & & $\begin{array}{l}\text { Cholesterol } \\
\text { (mg/roo g } \\
\text { liver)* }\end{array}$ & $\begin{array}{l}\text { acids } \\
\text { (g/roo } \mathrm{g} \\
\text { liver) }^{*}\end{array}$ & $\begin{array}{l}\text { Iodine value } \\
\text { for total } \\
\text { fatty acids* }\end{array}$ & Dienoic & Trienoic & $\begin{array}{l}\text { Tetra- } \\
\text { enoic }\end{array}$ \\
\hline $16 r(9)$ & $24 \%$ margarine $M_{1}$ & 653 & 4.78 & $83 \cdot 0$ & $16 \cdot 2$ & $2 \cdot 5$ & $3 \cdot 0$ \\
\hline $162(9)$ & $24 \%$ margarine $\mathrm{M}_{2}$ & 853 & $4 \cdot 40$ & $84 \cdot 3$ & $13 \cdot 2$ & $I \cdot 9$ & $2 \cdot 2$ \\
\hline $163(9)$ & $24 \%$ margarine $M_{3}$ & 705 & $4 \cdot 65$ & $93 \cdot 3$ & $28 \cdot 7$ & $I \cdot I$ & $4 \cdot 5$ \\
\hline $164(7) \dagger$ & $24 \%$ butter & 2729 & $6 \cdot 17$ & $71 \cdot 6$ & $6 \cdot 8$ & 0.9 & $4^{\circ} \circ$ \\
\hline $165(9)$ & $20 \%$ arachis oil & $86 I$ & $4^{\cdot 68}$ & $90 \cdot 4$ & $24 \cdot 4$ & $0 \cdot 4$ & $5 \cdot 3$ \\
\hline \multicolumn{2}{|c|}{ Standard error $(\%)$} & \pm 13 & \pm 6 & \pm 2 & \pm 5 & \pm Io & \pm 5 \\
\hline
\end{tabular}

Figures in parentheses are the numbers of animals in each group.

* Geometrical mean values.

+ Two animals died before the end of the experiment.

Table 3. Mean values for serum cholesterol, total serum fatty acids and polyenoic fatty acids in the serum fatty acids of rabbits after 42 weeks

\begin{tabular}{|c|c|c|c|c|c|c|}
\hline \multirow[b]{2}{*}{ Group no. } & \multirow[b]{2}{*}{ Dietary fat } & \multirow{2}{*}{$\begin{array}{l}\text { Cholesterol } \\
(\mathrm{mg} / \mathrm{roo} \mathrm{ml})^{*}\end{array}$} & \multirow{2}{*}{$\begin{array}{c}\text { Total } \\
\text { fatty acids } \\
(\mathrm{mg} / \mathrm{ro0} \mathrm{ml})^{*}\end{array}$} & \multicolumn{3}{|c|}{$\begin{array}{l}\text { Polyenoic fatty acids } \\
\text { (g/100 g fatty acids) }\end{array}$} \\
\hline & & & & Dienoic & Trienoic & Tetraenoic \\
\hline I6I (5) & $24 \%$ margarine $\mathrm{M}_{1}$ & 108 & $44 \cdot 6$ & $2 \mathrm{I} \cdot 5$ & $\circ$ & $I \cdot I$ \\
\hline $162(6)$ & $24 \%$ margarine $\mathrm{M}_{2}$ & 224 & $26 \cdot 4$ & $16 \cdot 3$ & 0 & $x \cdot x$ \\
\hline $163(6)$ & $24 \%$ margarine $\mathrm{M}_{3}$ & 157 & $44^{\cdot} \cdot 1$ & $3^{6 \cdot 1}$ & $\circ$ & $\mathbf{I} \cdot 9$ \\
\hline $164(6)$ & $24 \%$ butter & 562 & $90 \cdot 6$ & $\mathrm{I}_{4} 3$ & $\circ$ & 3.9 \\
\hline $165(6)$ & $20 \%$ arachis oil & 88 & 30.5 & $26 \cdot 5$ & $\circ$ & $1 \cdot 6$ \\
\hline \multicolumn{2}{|c|}{ Standard error (\%) } & \pm 27 & \pm 35 & - & 一 & - \\
\hline
\end{tabular}

Figures in parentheses are the numbers of analyses in each group. Only five or six analyses for seven to nine samples from each group were completed.

* Geometrical mean values.

has been possible to calculate an estimate of the variance common to all groups (a weighted mean of the individual values). On the basis of this estimation the standard error of the logarithmic means has been computed. The mean of the logarithmic values has been transformed to the corresponding antilogarithmic values (to give the geometrical means of the original values). The standard errors were accordingly transformed into percentage values, which are listed in the appropriate tables. These values are for nine animals in Tables 2 and 4 , and six animals in Table 3. 


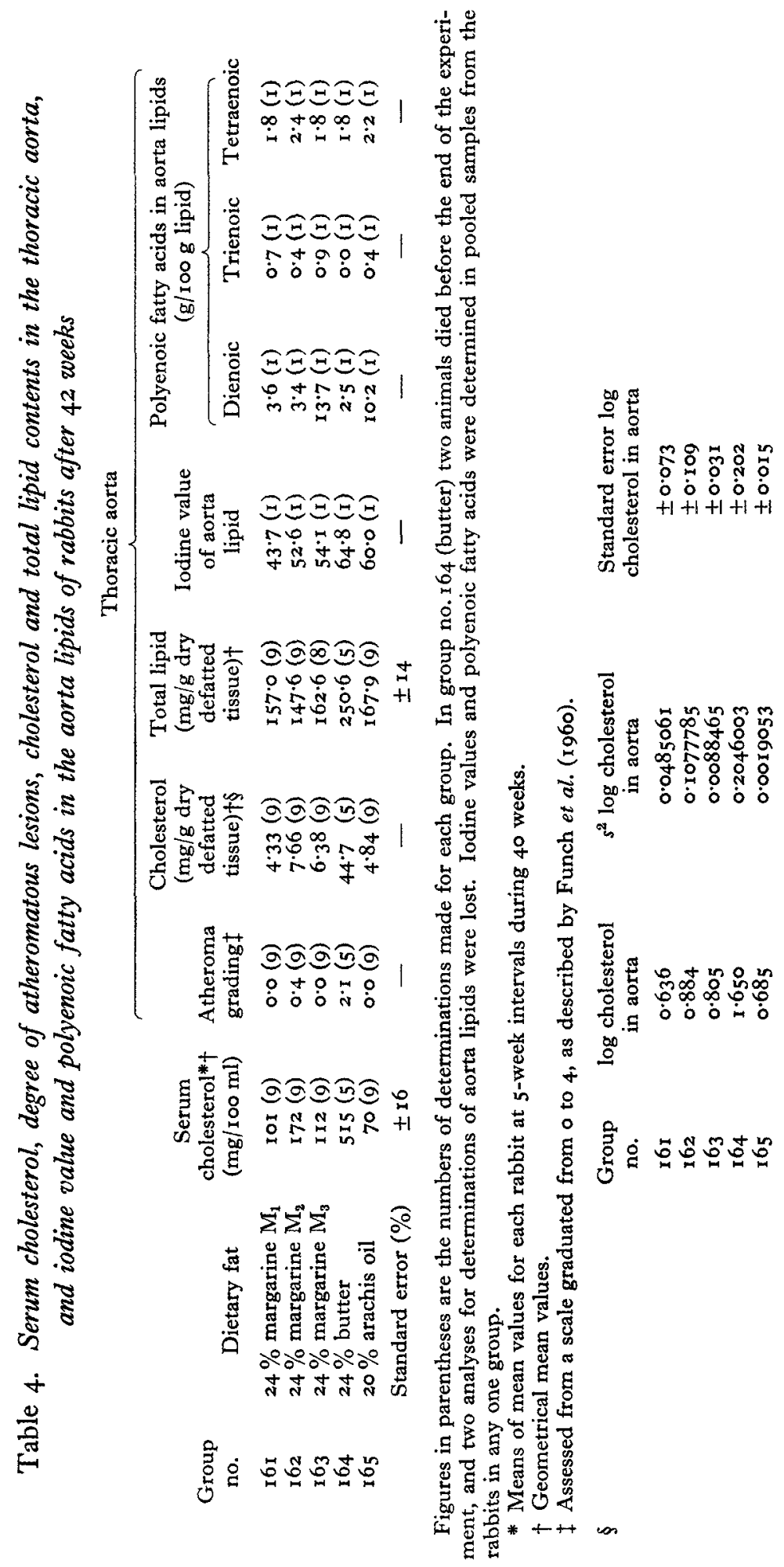




\section{RESULTS AND DISCUSSION}

\section{Liver lipids}

Mean values for liver cholesterol, liver total fatty acids and iodine value, as well as polyenoic fatty acids in the liver fatty acids, are shown in Table 2 . The rabbits fed on butter (group I64) had significantly higher contents of cholesterol $(P<0.001)$ and total fatty acids $(P<0$ or $)$ in the liver than those in the other groups. These findings correlate with the development of grossly fatty livers in all the rabbits given butter, whereas the livers of the rabbits given the other fats appeared normal (Funch et al. 1960).

The iodine value of the total liver fatty acids from the rabbits given butter was significantly $(P<0.001)$ lower than in all other groups, whereas the iodine values for the rabbits given margarine $M_{1}$ (group 161 ) or margarine $M_{2}$ (group 162 ) were significantly $(P<0.01)$ lower than for those given margarine $\mathrm{M}_{3}$ (group I63) or arachis oil (group I 65). This finding shows that there was a correlation between the iodine values of the fats (see Table I) given to the rabbits and the iodine values of their liver fatty acids.

It can further be seen from Table 2 that the contents of dienoic fatty acids in the liver fatty acids were lowest in the rabbits given butter and highest in those given margarine $M_{3}$. All the differences in the dienoic-acid contents between the groups were significant $(P<0.05$ for group $x 63 v$. group 165 and $P<0.01$ for all the other combinations of groups).

On comparing the content of dienoic fatty acids in the liver fatty acids with those in the fats given to the different groups for the last 16 weeks of the experiment (see Table I), it can be seen that a correlation existed between the amounts of dienoic fatty acids in the liver fatty acids of the rabbits and the amounts of dienoic fatty acids in the fats given to them.

The contents of trienoic and tetraenoic fatty acids in the livers of the rabbits given butter were not significantly $(P>0.05)$ different from those of the rabbits given margarine $\mathrm{M}_{3}$, and the trienoic fatty acids in the livers of the rabbits given margarine $\mathrm{M}_{1}$ were not significantly $(P>0 \cdot 05)$ different from those of rabbits given margarine $\mathrm{M}_{2}$, but all the other combinations of groups showed differences that were significant $(P<0.05)$. The liver content of trienoic fatty acids was highest in the rabbits given margarine $M_{1}$ and lowest in those given arachis oil, whereas the liver content of tetraenoic fatty acids was highest in those given arachis oil and lowest in those given margarine $\mathrm{M}_{2}$.

\section{Serum lipids}

Mean values for total serum fatty acids and polyenoic fatty acids in the serum fatty acids, as well as for serum cholesterol of the rabbits for which the analyses for serum fatty acids were completed, are presented in Table 3 . The rabbits given butter developed hypercholesterolaemia. Those given margarine $M_{1}$ or $M_{3}$ or arachis oil had a relatively low content of cholesterol in the serum, and margarine $M_{2}$ induced intermediate serum cholesterol values. A more detailed presentation of the serum 
cholesterol values is included in the paper of Funch et al. (1960). The content of total fatty acids in the serum was highest in the rabbits given butter but, because of the large variation within the groups, the differences between the contents of total fatty acids in the serum were only significant between the groups given butter and margarine $\mathrm{M}_{2}(P<0 \cdot 0 \mathrm{I})$.

The rabbits given butter had the lowest content of dienoic fatty acids and the highest content of tetraenoic fatty acids in the serum fatty acids; those given margarine $M_{3}$ had the highest content of dienoic fatty acids. Comparison between the contents of dienoic and tetraenoic fatty acids in the serum fatty acids and in the fats given to the rabbits during the last $\mathrm{I} 6$ weeks of experiment (see Table $\mathrm{I}$ ) showed a correlation between the amounts of these fatty acids in the serum fatty acids and in the dietary fats.

\section{Serum cholesterol, atheroma grading and aorta lipids}

Mean values for serum cholesterol, degree of atheromatous lesions, cholesterol and lipid contents in the thoracic aorta and iodine values as well as for the contents of polyenoic fatty acids in aorta lipids are listed in Table 4 . The serum cholesterol values in this table are means for each rabbit at 5 -week intervals over 40 weeks. These values rather than the values obtained at the end of the experiment were used; if the serum cholesterol level is of importance in determining the degree of atherosclerosis, the greatest significance must be attributed to cholesterol levels that have been elevated for the longest times.

It can be seen from Table 4 that the high serum cholesterol values of the rabbits given butter were associated with marked atherosclerosis in the aortas. The mean terminal grading of the severity of the lesions was $2 \cdot I$. The intermediate serum cholesterol values of the rabbits given margarine $\mathrm{M}_{2}$ were associated with the appearance of some atheromatous lesions in about half the rabbits. The mean terminal grading was 0.4 . The rabbits given the other margarines or arachis oil had a relatively low content of cholesterol in the serum and developed no gross lesions. Further, it can be seen that the severity of atherosclerosis was correlated with the cholesterol content of the aorta. Thus the macroscopically normal aortic tissue contained 4.33 , 6.38 or $4.84 \mathrm{mg}$ cholesterol/g dry defatted tissue, whereas the values for the aortas with a low or high grade of atheromatous lesions were 7.66 and $44.7 \mathrm{mg} / \mathrm{g}$, respectively.

A statistical treatment of the relation between visual grading of atherosclerosis and the cholesterol content of the serum and of the dry defatted aortic tissue in this experiment can hardly be justified, because only a limited number of the rabbits developed grossly visible lesions in the aorta and also because two samples for the determinations of aortic cholesterol were lost. Only one or two values for cholesterol in the serum and the aorta were within each of the arbitrary grades $1,2,3$ and 4 for visual grading of atherosclerosis, and thirty-four rabbits had no visible lesions in the aorta. Nevertheless, it can be seen from Fig. I that the serum cholesterol level gave a good index of whether or not conditions were favourable for the development of atherosclerosis. However, the exact degree of atherosclerosis associated with a high value for cholesterol in the serum could not be predicted in individual rabbits, as it appeared that some rabbits were more susceptible than others at the same serum cholesterol level. 
The association in our experiments between high serum cholesterol values and atherosclerosis in the aorta is in agreement with the experiments of Day \& Wilkinson (1956) with cholesterol-fed rabbits and with the experiments of Wigand (1959) with

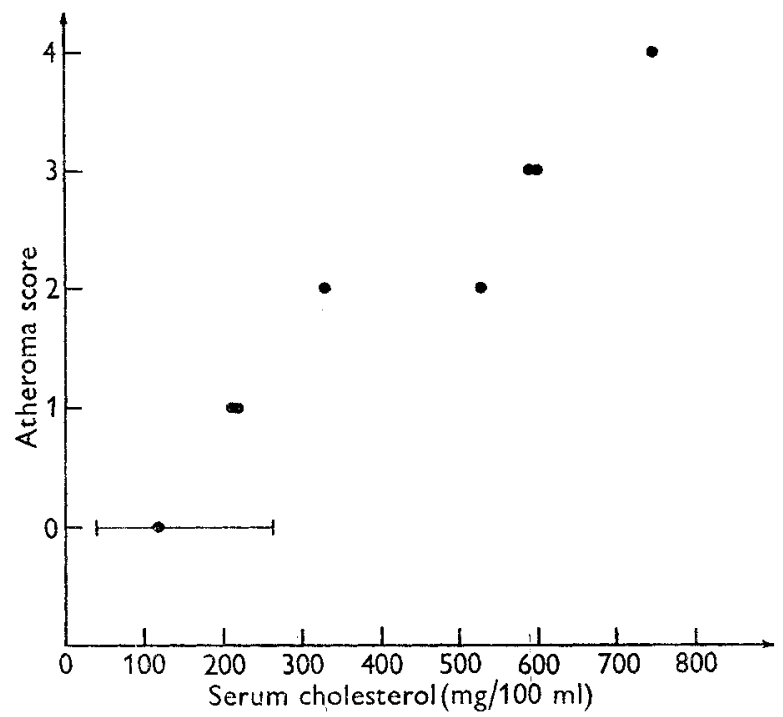

Fig. x. Relation between degree of atheromatous lesions in thoracic aorta of rabbits after 42 weeks and their serum cholesterol values, which are the means of the values for each rabbit at 5 -week intervals over 40 weeks. For atheroma scores $\mathrm{r}-4$ each point represents the score and the value for cholesterol in the serum of one rabbit. Score o is plotted against the mean value for cholesterol in the serum of thirty-four rabbits. The range of values is shown.

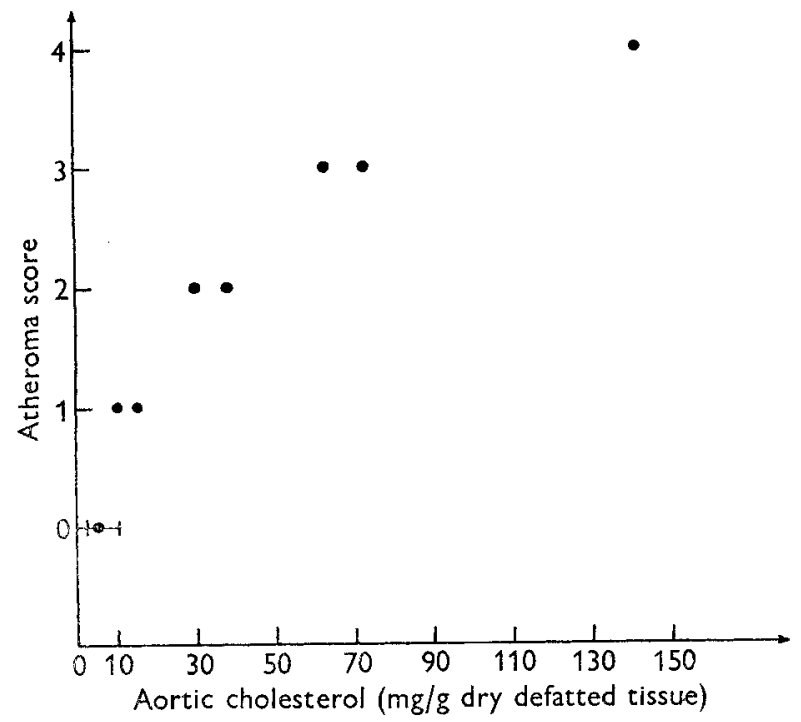

Fig. 2. Relation between degree of atheromatous lesions and cholesterol content in the thoracic aorta of rabbits after 42 weeks. For atheroma scores $I-4$ each point represents the score and the value for cholesterol in the aorta of one rabbit. Score 0 is plotted against the mean value for cholesterol in the aorta of thirty-four rabbits. The range of values is shown. 
rabbits fed on purified diets containing fat without added cholesterol. They found a statistically significant correlation between total cholesterol in the serum and the severity of atheromatous lesions in the aorta.

From Fig. 2 it can be seen that there was a good correlation between the visual grading of atheromatous lesions in the thoracic aorta and the cholesterol content of the dry defatted tissue. This result is in accordance with that of Day \& Wilkinson (1956), who found a close correlation between the aorta grading and the content of cholesterol per aorta. These authors state that this is perhaps what could be expected. The lesions consist mostly of cholesterol and therefore, with careful grading taking into account all factors, the chemical estimations must mirror this grading.

It is seen from Table 4 that the rabbits given butter apparently had the highest content of total lipid in the aorta. The difference from the other groups was only on the borderline of significance $(P=0.05)$. The iodine value of the aorta lipid was highest in the rabbits given butter and lowest in those given margarine $M_{1}$. Dienoic fatty acids in the aorta lipid reflected the pattern of these compounds found in the dietary fats. The low contents of dienoic and trienoic fatty acids in aorta lipid from the rabbits given butter indicate that a high iodine value was ascribed to a high content of monoenoic fatty acids in the aorta lipid from these rabbits.

\section{SUMMARY}

I. The object of the experiment reported was to investigate in male rabbits, given ad lib. purified diets containing $20 \%$ fat without added cholesterol, the influence of $(a)$ arachis oil, $(b)$ butter, and $(c)$ three mixtures of fats made into margarines on the development of atherosclerosis and on the cholesterol levels and fatty-acid composition of the liver, serum and aorta after a feeding period of 42 weeks. The rabbits, 6 months old, were distributed over five groups of nine animals each.

2. The rabbits given the diet containing butter developed significantly higher cholesterol concentrations in serum, aorta and liver, with more aortic atheroma, than the rabbits given diets containing the margarines or arachis oil.

3. The serum cholesterol concentrations gave a good index of whether or not conditions were favourable for the development of atherosclerosis, and the visual grading of atherosclerosis was correlated with the aorta cholesterol content.

4. In analyses for polyunsaturated fatty acids in liver, serum and aorta the dienoic acid content reflected the pattern of these compounds in the dietary fats.

\section{REFERENCES}

Day, A. J. \& Wilkinson, G. K. (1956). Aust. F. exp. Biol. med. Sci. 34, 423.

Funch, J. P., Krogh, B. \& Dam, H. (1960). Brit. F. Nutr. 14, 355.

Hald, A. (1952a). Statistical Theory with Engineering Applications, p. 292. New York: John Wiley and Sons Inc.

Hald, A. $(1952 b)$. Statistical Tables and Formulas. New York: John Wiley and Sons Inc.

Hammond, E. G. \& Lundberg, W. O. (1953). F. Amer. Oil Chem. Soc. 30, 433.

Herrmann, R. G. (1957). Proc. Soc. exp. Biol., N.Y., 94, 503.

Wigand, G. (1959). Acta med. scand. 166, Suppl. no. 35 I. 